\title{
Interação Comunicativa em Contexto Lúdico de Duas Crianças com Síndrome de Down, Comportamentos Autísticos e Privação de Estímulos
}

\author{
Communicative Interaction in a Playful Context of Two Children \\ with Down Syndrome, Autistic Behavior and Deprivation of Stimuli
}

\author{
Glenda Saccomano Castro*, ${ }^{*}$ Ivone Panhoca ${ }^{b}, \&$ Maria de Lurdes Zanolli ${ }^{a}$ \\ ${ }^{a}$ Universidade Estadual de Campinas, Campinas, Brasil \\ $\&{ }^{b}$ Universidade de Mogi das Cruzes, Mogi das Cruzes, Brasil
}

\begin{abstract}
Resumo
Esta pesquisa qualitativa teve como objetivo analisar o processo de interação comunicativa entre duas crianças que apresentam comportamentos autísticos associados à síndrome de Down e entre estas e a terapeuta, enfocando modalidades de comunicação verbal e não-verbal estabelecidas durante brincadeiras de faz-de-conta. As duas crianças têm histórias de vida com privação de estímulos. Os dados foram coletados em sessões fonoaudiológicas semanais durante 6 meses. Após a transcrição dos episódios, a partir da vídeo-gravação das sessões realizadas, as análises evidenciaram desenvolvimento qualitativo na interação comunicativa entre as crianças e a terapeuta, possibilitando o compartilhamento de significados e inserção destes sujeitos nas situações sociais apresentadas.

Palavras-chave: Desenvolvimento Cognitivo; Síndrome de Down; Interação Comunicativa; Autismo; Brincadeira de Faz-de-Conta.
\end{abstract}

\begin{abstract}
The objective of this qualitative research was to analyze the communicative interaction process between two children who show autistic behavior associated with Down syndrome, as well as the process between them and their therapist. Different modalities of verbal and non-verbal communication demonstrated during make-believe activities were also observed. Both children have life history of deprivation of stimuli. Data were collected during weekly sessions with a speech therapist over 6 months. The sessions were video-taped and then the episodes were transcribed. The analyses displayed a qualitative development in the communicative interaction between the children and the therapist which favored the subjects to share meanings and insert themselves in the social situations presented.

Keywords: Cognitive Development; Down Syndrome; Communicative Interaction; Autism; Make-Believe Activities.
\end{abstract}

São escassos os trabalhos que visam analisar as formas de expressões comunicativas em sujeitos com síndrome de Down (Andrade \& Limongi, 2007; Freitas \& Dainêz, 2006). Além disso, embora existam pesquisas, principalmente internacionais, que relatam a presença de autismo em sujeitos com esta síndrome (Castillo et al., 2008; Kent, Perry, \& Evans, 1998; Starr, Berument, Tomlins,
Papanikolaou, \& Rutter, 2005), não foram encontrados estudos específicos do processo terapêutico de crianças com este diagnóstico.

Desta forma, apresentamos neste artigo uma pesquisa participante que teve como objetivo analisar o processo de interação comunicativa entre duas crianças com síndrome de Down e comportamentos autísticos, com idades de 9 e 12 anos, e entre estas e a terapeuta fonoaudióloga, enfocando modalidades de comunicação verbal e não-verbal estabelecidas durante brincadeiras de faz-de-conta. Estas crianças apresentam histórias de vida peculiares que configuram quadros importantes do ponto de vista sócio-histórico-afetivo: uma delas reside em um orfanato desde os 3 meses de idade e a outra reside com a avó paterna (que apresenta problemas de alcoolismo), por determinação judicial, devido a uma história con- 
turbada de episódios de agressão, rejeição e negligência por parte da mãe.

O objetivo de realizar esta pesquisa foi despertado por vários questionamentos que surgiram anteriormente: Como se dá o processo de interação comunicativa destas duas crianças com síndrome de Down e comportamentos autísticos? Como estas crianças se comunicam em atividades interativas? Os comportamentos autísticos poderiam estar relacionados às privações de estímulos a que as crianças foram submetidas e às condições ambientais desfavoráveis para seu desenvolvimento global?

A partir do aparecimento dessas questões, a base teórica eleita para nortear a pesquisa qualitativa foi a perspectiva histórico-cultural (Vigotski, 1984/2007), que tem como pressuposto o desenvolvimento mental humano concebido por um processo cultural, considerando-se o desenvolvimento das funções psíquicas superiores (memória, atenção voluntária, linguagem, pensamento) a partir das interações sociais mediadas pela linguagem.

\section{A Interação Social e a Comunicação em Crianças com Desenvolvimento Típico}

A inserção de um bebê na cultura passa fundamentalmente pela mediação dos signos, principalmente pela linguagem (sob formas variadas) e pela mediação do outro, detentor da significação (Pino, 2005). De acordo com Borges e Salomão (2003), para o bebê com desenvolvimento típico, os gestos, as expressões faciais e o olhar se apresentam como formas de comunicar intenção e, juntamente com esta comunicação não-verbal, vocalizações passam a ser produzidas com marcação de entonações. Para Klin (2006), desde o nascimento estas crianças apresentam interesse na interação e no ambiente social, sua socialização com o outro inicia o desenvolvimento das habilidades sociais cognitivas, simbólicas e de comunicação.

De acordo com Tomasello (2003), bebês com desenvolvimento típico apresentam inicialmente interações com objetos agarrando-os e manipulando-os, além de interagirem com outras pessoas, como por exemplo, quando levantam os braços para o adulto quando querem ser carregados. Posteriormente tais comportamentos passam a envolver "uma coordenação de suas interações com objetos e pessoas resultando num triângulo referencial composto de criança, adulto e objeto ou evento ao qual dão atenção" (Tomasello, 2003, p. 85). Estas interações sociais podem ser chamadas de atenção conjunta, na qual sujeitos prestam atenção em uma terceira pessoa ou objeto por um período razoável de tempo, sendo definidas intencionalmente (Tomasello, 2003).

Para Vigotski (1984/2007), no desenvolvimento da criança, o seu movimento, como por exemplo, o ato de apontar, que inicialmente é uma tentativa de alcançar algo (movimento orientado para um determinado objeto), passa a ser interpretado pelo outro (mãe) atribuindo a esse movimento um significado. Assim, à medida que a criança associa seu movimento a uma reação do outro, reconhece este movimento como um gesto de apontar e começa a utilizá-lo intencionalmente. Nota-se, portanto, que, uma operação que inicialmente representa uma atividade externa, passa a ocorrer internamente na criança.

\section{Comportamentos Autísticos na Síndrome de Down e Interação Comunicativa: Para uma Visão Além da Biológica}

De acordo com Andrade e Limongi (2007), o desenvolvimento cognitivo de crianças com síndrome de Down ocorre como na criança com desenvolvimento típico, porém é mais lento e atrasado. A criança com esta síndrome apresenta uma capacidade compreensiva superior a de expressão e, devido à dificuldade com a linguagem oral, os gestos, assim como o contato visual e sorriso, podem ser úteis e servirem com um importante meio de comunicação.

As leis que regem o desenvolvimento cognitivo são as mesmas para todas as pessoas, independentemente se apresentam algum tipo de deficiência ou não. De acordo com Vigotski (1997), em sua obra "Fundamentos de Defectologia", a criança cujo desenvolvimento está comprometido por algum tipo de déficit não é necessariamente menos desenvolvida que seus pares normais, sendo apenas uma criança que se desenvolve de outro modo. A lei central de suas proposições é a de que qualquer deficiência origina uma tendência ou estímulo para a formação da compensação, isto é, a insuficiência de uma capacidade é compensada com o desenvolvimento de outra. Tal compensação não é orgânica, mas relativa ao funcionamento psicológico, em uma idéia que corresponde à plasticidade dos processos de desenvolvimento.

É essencial considerar que a criança com síndrome de Down, que apresenta deficiência mental, não deve ser observada somente por suas alterações orgânicas ou cognitivas, pois ela não se reduz ao déficit. Para Vigotski (1997) nota-se que a criança age sobre este déficit, procurando maneiras para se reorganizar e se equilibrar, superando-se, compensando ou adaptando-se à sua deficiência.

Todas as crianças se desenvolvem devido a seus atributos pessoais (físico e mental) e ao meio social na qual estão inseridas. Segundo Halpern e Figueiras (2004), os resultados negativos, as dificuldades que surgem no desenvolvimento infantil podem ser produzidas por problemas genéticos e biológicos adquiridos, porém podem ocorrer também pela ausência de oportunidades esperadas. Para De Carlo (1999), "a influência de um meio desfavorável pode agravar os comprometimentos do desenvolvimento (gerando complicações secundárias), como também pode ser a desencadeadora de quadros que passam a ser classificados como sendo de deficiência" (p. 66).

Embora existam idéias pré-concebidas que generalizam o comportamento de sujeitos com síndrome de Down, sendo vistos como afetuosos, brincalhões, bons imitadores, apreciadores da música etc, não se pode criar um 
estereotipo, um padrão previsível, visto que o comportamento e o desenvolvimento cognitivo não dependem somente da alteração cromossômica, mas também do potencial da herança genética e das influências do meio social no qual estão inseridos (Rodrigues \& Alchieri, 2009).

Mesmo sendo pouco comum, crianças com síndrome de Down podem apresentar, por exemplo, transtornos invasivos do desenvolvimento, como o autismo (Cunningham, 2008). Embora existam poucas informações sobre o autismo em sujeitos com síndrome de Down, um número crescente de pesquisas internacionais tem sugerido que esta associação pode ser mais comum do que geralmente se pensava (Castillo et al., 2008; Kent et al., 1998; Starr et al., 2005). Para Subirachs (2005), de 5 a $9 \%$ das crianças com síndrome de Down podem apresentar o autismo associado. Em uma pesquisa realizada com 13 indivíduos com síndrome de Down, com média de idade de 14 anos e 6 meses, 5 deles apresentaram autismo, e destes somente 1 apresentou habilidade verbal (Starr et al., 2005). Em outro estudo, foram relatados 3 casos de sujeitos com síndrome de Down com diagnóstico de autismo realizado de acordo com o CID-10 (Kent et al., 1998).

Os diagnósticos médicos realizados dentro do espectro autístico normalmente são baseados nos critérios mais utilizados, estabelecidos pelo Manual Diagnóstico e Estatístico dos Distúrbios Mentais - DSM-IV, da American Psychiatric Association (APA, 1995) ou pela Classificação de Transtornos Mentais e de Comportamento da CID10, da Organização Mundial da Saúde (OMS, 1993). De acordo com estes métodos adotados para o diagnóstico psiquiátrico, há prejuízos qualitativos na comunicação (verbal e não-verbal); na interação social recíproca; além da presença de atividades, interesses e comportamentos restritos, repetitivos e estereotipados. Observam-se ainda dificuldades em brincadeiras de faz-de-conta e jogos sociais de imitação (Gadia, Tuchman, \& Rotta, 2004; OMS, 1993). Segundo Gadia et al. (2004), as crianças com autismo apresentam déficits qualitativos na interação sendo possível observar pouco contato visual; problemas com atividades grupais; tendência ao isolamento. Apresentam ainda dificuldades em focar espontaneamente a atenção visual com o outro e atrair a atenção destes para a realização de algo (Passerino \& Santarosa, 2007).

Porém, mesmo existindo listas de comportamentos utilizadas como critérios para incluir um sujeito no espectro autístico, incluindo aqueles que apresentam síndrome de Down, cabe ressaltar neste artigo que um sujeito não se constitui apenas por um diagnóstico, suas possibilidades de desenvolvimento não são determinadas somente por ele. O que decide o destino da personalidade não é o defeito em si, mas suas consequências sociais, sua realização sociopsicológica (Vigotski, 1997).

Crianças pequenas que sofreram privações de estímulos podem apresentar, por exemplo, comportamentos autísticos, caracterizados por déficits de interação social, linguagem e alterações de comportamento (Coelho, Iemma, \& Lopes-Herrera, 2008). De acordo com Ballone (2004), as alterações no desenvolvimento de uma criança, devido à negligência precoce da mãe, podem ocorrer não somente pela falta de nutrição e/ou higiene, mas também, e principalmente, pela falta de estímulos, contatos emocionais e afetivos.

Skuse (2002), ao descrever estudo de casos de negligência e privação extrema, relatou a história de uma garota que sofreu negligência por parte da mãe nos primeiros anos de vida. Aos 2 anos e 4 meses foi levada, juntamente com sua irmã (14 meses mais velha), à um orfanato pelo assistente social. Apresentava inúmeros comportamentos autísticos, sendo observadas, por exemplo, ausência de linguagem oral e de brincadeiras, além de falta de reação a estímulos sonoros. Inicialmente, logo após ter sido encontrada, recebeu terapia fonoaudiológica, porém, por ter conseguido um pequeno progresso a terapia foi abandonada. Por volta dos 9 anos, a falta relativa de comunicação social e linguagem foi relacionada ao autismo, porém quatro anos mais tarde apresentou uma evolução notável nestas áreas, coincidindo com o desaparecimento dos traços autistas. Embora tenha sido colocada em vários orfanatos naquele período, segundo o autor, os relatórios sugerem que ela recebeu algum tipo de fonoterapia consistente com evolução em suas atitudes sociais. Para Skuse (2002), "esta observação é importante por si só, pois sugere que um posterior progresso pode ser feito com crianças muitos anos após a remoção da privação" (p. 48).

Assim, observa-se a necessidade de práticas terapêuticas que estejam direcionadas para a superação dessas dificuldades, considerando o potencial destas crianças e não suas deficiências orgânicas, cognitivas ou desvios psicossociais. Deste modo, para o favorecimento de interações comunicativas, a brincadeira aparece como uma atividade importante para o desenvolvimento destes sujeitos. O brincar pode ser considerado um fator essencial por permitir a ampliação da experiência do sujeito (Pinto \& Góes, 2006), auxiliando na constituição social, motora, afetiva e cognitiva da criança (Hueara, Souza, Batista, Melgaço, \& Tavares, 2006). Segundo Alves, Dias e Sobral (2007), a brincadeira de faz-de-conta aparece, portanto, como uma atividade com significações sociais que privilegia o incentivo ao pensamento abstrato, fundamentalmente a partir de construções imaginárias, além de possibilitar as interações sociais e o compartilhamento de signos.

Para Fernandes (2004) as propostas realizadas com crianças autistas visando a facilitação de habilidades sociais devem envolver duplas ou pequenos grupos. De acordo com a autora, as atividades lúdicas com outras crianças são importantes para um repertório comunicativo expansivo e diversificado de crianças com autismo.

Assim, as duas crianças deste estudo foram analisadas em atividades que incentivavam, em especial, a imagina- 
Castro, G. S., Panhoca, I., Zanolli, M. L. (2011). Interação Comunicativa em Contexto Lúdico de Duas Crianças com Síndrome de Down, Comportamentos Autísticos e Privação de Estímulos.

ção, sempre com olhar voltado para suas possibilidades interacionais e comunicativas. Considerou-se o potencial das duas crianças e não suas deficiências orgânicas, cognitivas ou desvios psicossociais e o referencial teórico eleito serviu, então, como base para a pesquisa por priorizar as possibilidades de comunicação, considerando as condições sociais de sua produção.

\section{Método}

Este estudo foi realizado com uma fundamentação teórico-metodológica a partir da abordagem históricocultural, que considera o desenvolvimento humano um processo que se dá nas interações sociais. O tipo de pesquisa qualitativa realizada é a pesquisa participante, que segundo Gori (2006), se configura como um método que insere o pesquisador no campo investigado, fazendo com que este se torne parte do universo da pesquisa.

A pesquisa foi submetida ao Comitê de Ética em Pesquisa da Faculdade de Ciências Médicas da Universidade Estadual de Campinas (Unicamp) e aprovada com o parecer de número 638/2007. Além disso, o estudo foi iniciado mediante autorização da coordenação da instituição especial e consentimento (assinatura do Termo de Consentimento Livre e Esclarecido) dos responsáveis pelas crianças.

\section{Participantes}

A pesquisa foi realizada em uma Instituição especial localizada no interior do Estado de São Paulo. Foram selecionadas intencionalmente duas crianças, uma do sexo masculino e uma do sexo feminino, com 9 e 12 anos respectivamente, que apresentavam diagnóstico médico psiquiátrico de autismo associado a síndrome de Down (CID-10) e histórias de vida com sofrimento afetivo. Estas crianças frequentavam diariamente esta Instituição, em período integral, e passavam por atendimentos terapêuticos semanais neste local.

Visando a preservação da identidade dos sujeitos envolvidos nesta pesquisa optou-se pela utilização de siglas para nomeá-los: V. e P.

Criança $V$. - sexo masculino, com 9 anos na época da pesquisa. Reside em um orfanato sob a responsabilidade de "pais sociais", que são substituídos de tempos em tempos (o que configura um quadro importante do ponto de vista sócio-histórico-afetivo). Foi levado ao orfanato aos três meses de idade pela mãe biológica que apresenta deficiência mental. Possui três irmãos que também residem no orfanato. A criança faz uso de um medicamento neuroléptico de acordo com prescrição médica e apresenta diagnóstico médico psiquiátrico de autismo associado à síndrome de Down (CID-10), apresentando comportamentos autísticos tais como: alterações de linguagem (ausência de oralidade), busca de isolamento, pouco contato visual e transtornos do comportamento (agitação psicomotora e estereotipias).
Criança $P$. - sexo feminino, com 12 anos na época da pesquisa. Criança com síndrome de Down, passou a fazer acompanhamento médico psiquiátrico quando tinha 6 anos em um ambulatório de saúde mental devido ao diagnóstico de autismo, fazendo uso de medicamento neuroléptico. Encontra-se sob a guarda da avó paterna por determinação judicial devido a uma história de vida conturbada com episódios de agressão, rejeição e negligência por parte da mãe. Atualmente reside com esta avó (que apresenta problemas de alcoolismo) e com a tia que tem deficiência mental.

Apresentava dificuldades de interação com o outro (terapeuta e criança), sendo possível notar episódios de agressividade; dificuldade em manter a atenção; interesse em girar objetos; emissão de sons e movimentos estereotipados; dificuldade na comunicação e no brincar. Durante avaliação terapêutica observou-se início da comunicação verbal e utilização de alguns brinquedos com finalidade simbólica.

\section{Coleta e Análise dos Dados}

Em um primeiro momento foram realizadas anamneses com os responsáveis pelas crianças, bem como a observação de relatórios terapêuticos e diagnósticos médicos, disponíveis nos prontuários da Instituição.

As duas crianças selecionadas para esta pesquisa passaram por atendimentos fonoaudiológicos semanais, com aproximadamente uma hora de duração cada, totalizando 28 sessões. Tais situações terapêuticas foram videogravadas com o auxílio de uma filmadora e posteriormente foram transcritas (transcrição ortográfica da fala da terapeuta e de uma das crianças, acompanhadas de observações e comentários relativos às ações e comunicação não-verbal das crianças e terapeuta).

As atividades simbólicas realizadas durante o período dos atendimentos terapêuticos para a coleta dos dados deste estudo, pela terapeuta-pesquisadora, envolveram situações imaginárias, mais precisamente, brincadeiras de faz-de-conta.

A análise dos dados coletados, a partir das 28 sessões terapêuticas transcritas, foi realizada dando-se atenção aos detalhes, considerando os sujeitos, as relações intersubjetivas e as condições sociais da situação (Góes, 2000). Para isto, foram tomados como pressupostos, tanto as premissas da "análise microgenética", cujo enfoque são os detalhes das ações, o recorte de episódios interativos, as interações e cenários socioculturais; como as formulações do paradigma indiciário que apontam para a importância dos pormenores, de indícios e, apesar de privilegiar o singular, evidencia a ideia de totalidade (Góes, 2000).

\section{Resultados}

Foram selecionados quatro episódios que representam o processo evolutivo das duas crianças, de acordo com o objetivo proposto. A transcrição foi realizada com a utili- 
zação dos sinais mais frequentes e úteis propostos por Marcuschi (2007), tais como: (+): sinal para cada 0,5 segundo de pausa; letra MAIÚSCULA: ênfase ou acento forte; :: alongamento de vogal; (( )): comentários do analista; aspas duplas " : equivale ao ponto de interrogação e aspa simples' : algo como uma vírgula ou ponto-evírgula; ... indicação de transcrição parcial.

Nos episódios será utilizado: V. para a criança do sexo masculino, P. para a criança do sexo feminino e T. para a terapeuta (pesquisadora).

\section{Episódio 1-Referente à $1{ }^{a}$ Sessão Terapêutica}

Contexto: Foi disponibilizado às duas crianças um cesto com utensílios de cozinha em miniatura. A terapeuta faz-de-conta que está preparando uma comida no fogão.

T1: P: ((observa a ação da terapeuta e emite sons não interpretáveis, realizando movimentos de vai e vem com o corpo))

T2 T: o que você quer"

T3 P: ((em silêncio, sem olhar para a terapeuta, realiza movimentos estereotipados de vai e vem com o corpo))

T4 T: posso fazer" a tia tá fazendo comida ((com uma colher na mão aponta para a panela))

T5 P: tia ((chama a terapeuta sem olhar pra ela))

T6 T: oi (+) o que tem aqui" macarrão"

T7 P: ão ((não olha para a terapeuta))

T8 T: ((mexe uma colher na panela))

T9 P: ((volta a observar a ação da terapeuta e, irritada, emite sons não interpretáveis em tom de protesto))

(...)

T10 V: ((V. que manipulava uma batedeira observa P. mexendo uma colher na panela))

T11 P: ((leva a colher à boca de V.))

T12 V: ((abre a boca e rapidamente vira o rosto))

T13 T: o que você está fazendo"

T14 P: ((não olha para a T. e começa a procurar algo))

T15 T: o que tem aí" o que você tá procurando"

T16 P: ((não olha para a T., passa a colher em um prato e a leva novamente à boca de V.))

T17 V: ((olha para P., abre a boca, sorri e abaixa a cabeça rapidamente))

Observa-se neste primeiro episódio a prevalência de vocalizações na comunicação de P. Embora tenha apresentado, no turno 1 (T1), sons não interpretáveis juntamente com movimentos estereotipados, a terapeuta considera sua comunicação não-verbal e realiza uma tentativa de compreendê-la, atribuindo a ela uma função linguístico-interativa (turno 2). Logo em seguida, P. fica em silêncio e realiza movimentos estereotipados com o corpo (turno 3). Porém, a terapeuta volta a interagir verbalmente visando inseri-la na brincadeira de faz-de-conta (turno 4). Nota-se que neste momento P., mesmo sem manter contato ocular, chama por ela e tenta reproduzir uma palavra dita pela terapeuta (turnos 5 e 7). Quando a terapeuta desvia sua atenção para o brinquedo, $\mathrm{P}$. volta a emitir sons não interpretáveis em tom de protesto.
Mais adiante, P. demonstra iniciativa em interagir com a outra criança através de gestos representativos (turnos 11 e 16), porém não apresenta intenção de se comunicar com a terapeuta quando esta tenta participar da brincadeira de faz-de-conta através da comunicação verbal (turnos 13 e 15). Embora V. tenha procurado o isolamento aceita a aproximação da outra criança interagindo passivamente com ela (turnos 12 e 17).

\section{Episódio 2-Referente à $15^{a}$ Sessão Terapêutica}

Contexto: A terapeuta e as crianças brincam com utensílios de cozinha, casa de madeira com móveis e uma família de bonecos de pano. A terapeuta havia sugerido a elas o preparo de uma comida e posteriormente de um suco para os integrantes desta família.

T1 T: V $(+)$ a gente podia fazer um suco do que" você me ajuda" eu quero um suco de UVA

T2 V: ((continua brincado com o prato e garfo))

T3 T: e você P."

T4 P: mamãe

T5 T: você vai fazer pra mamãe"

T6 P: papai

T7 T: ah (+) você vai fazer pra mamãe $(+)$ pro papai ((olha para P.))

T8 P: mamãe

T9 T: mamãe

T10 P: papai

T11 T: papai $(+)$ vovó

T12 P: ((realiza meneio positivo com a cabeça))

T13 T: pro vovô $(+)$ pro bebê $(+)$ vamos fazer a comida pra eles né" então ó $(+)$ eu vou pegar aqui ((pega utensílios na cesta))

T14 P: aqui ó ((pega o garfo, faz-de-conta que está pegando comida do prato e leva à boca de $\mathrm{V}$.))

T15 V: ((aceita a aproximação de P. e abre a boca))

(...)

T16 V: ((passa a face de um fantoche em uma xícara)) T17 T: suco $(+)$ a vovó vai tomar $(+)$ olha lá o V. está dando suco pra vovó ((olha para P. e aponta para V.)) T18 P: ((olha para V.))

T19 T: a vovó vai tomar suco" hu::m que suco gostoso ((a T. vira-se para V. e o ajuda a fazer de conta que está dando suco para a boneca))

T20 V: ((pega uma colher e a leva à "boca" da boneca))

Neste episódio observa-se, a todo o momento, a terapeuta interagindo através de perguntas, visando incitar a comunicação das crianças (turnos 1, 3 e 5). Tal atitude faz com que P. interaja com ela através da comunicação verbal (turnos 4, 6, 8 e 10) e da comunicação não-verbal (turno 12). A partir disto, a terapeuta passa a atribuir sentido às colocações de P., contextualizando-as e interpretando-as (turnos 5, 7, 11 e 13). Deste modo, pode-se notar o desenvolvimento da comunicação verbal de P., passando a utilizar, com maior frequência, palavras monossilábicas visando ser compreendida (turnos 4, 6, 8 e 10).

Observa-se ainda neste episódio, a terapeuta mantendo a interação com as crianças. No turno 17 , ela atribui 
Castro, G. S., Panhoca, I., Zanolli, M. L. (2011). Interação Comunicativa em Contexto Lúdico de Duas Crianças com Síndrome de Down, Comportamentos Autísticos e Privação de Estímulos.

significado à ação de V. e chama a atenção da outra criança (P.) para tal evento, a partir da comunicação verbal e não-verbal (gesto indicativo). No turno 19, a terapeuta volta a interpretar o gesto de V. e o auxilia a utilizar o brinquedo com finalidade simbólica. A criança passa, então, a brincar com a terapeuta (turno 20), realizando outro tipo de gesto representativo dentro do contexto da brincadeira de faz-de-conta ("alimentar" a boneca).

\section{Episódio 3-Referente à $23^{a}$ Sessão Terapêutica}

Contexto: Sentados no centro da sala de terapia, a terapeuta interage com as crianças através de um fantoche. O cesto de brinquedos com utensílios de cozinha também estava disponível para as crianças.

T1 V: ((olha para a T., coloca uma parte de uma batedeira no interior da panela e a leva à boca da terapeuta))

T2 T: hu::m

T3 V: ((olha para o fantoche que está na mão da T., põe novamente o objeto na panela e em seguida o leva à "boca" dele))

T4 P: ((olha para V.))

T5 T: a P. também quer $(+)$ né P."

T6 P: ((olha para a T.))

T7 V: ((olha para P., coloca o objeto na panela e em seguida o leva até a boca de P.))

(...)

T8 T: vamos guardar estes brinquedos então"

T9 V: ((olha para a T.))

T10 T: vamos guardar" ((olha para V.))

T11 V: ((mantendo contato ocular com a T. realiza meneio negativo com a cabeça))

V. demonstra neste episódio, iniciativa comunicativa ao interagir com a terapeuta e seu fantoche através de gesto representativo, dentro do contexto da brincadeira de faz-de-conta (turnos 1 e 3). Além disso, a partir da tentativa da terapeuta de inserir P. na brincadeira (turno 5), V. interage também com a criança (turno 7). Pode-se notar a brincadeira simbólica de V., ao utilizar um objeto para representar outro, uma peça de batedeira de brinquedo se transforma, através de seus gestos, em uma colher (turnos 1, 3 e 7). Mais adiante a terapeuta se dirige novamente à $\mathrm{V}$. a partir de uma pergunta, considerando-o como um sujeito com possibilidades interacionais e comunicativas (turno 8). V. mostra-se receptivo à interação mantendo contato ocular e respondendo seu questionamento através de um gesto de negação com a cabeça (turno 11).

Observa-se, portanto, durante todo este episódio, a criança V. se colocando na brincadeira como um sujeito comunicativo, tendo iniciativa na interação com a terapeuta e a outra criança.

\section{Episódio 4-Referente à $28^{a}$ Sessão Terapêutica}

Contexto: A terapeuta e as crianças brincam com uma família de fantoches e com utensílios de cozinha.
T1 T: olá V. eu sou o papai ((movimenta o fantoche na frente de V. e faz-de-conta que ele está falando))

T2 V: ((com uma colher na mão olha para o fantoche))

T3 T: eu estou com uma fome' ((movimenta o fantoche e faz-de-conta que ele está falando))

T4 V: ((leva a colher até a boca do fantoche))

T5 T: ((emite sons como se estivesse comendo))

T6 P: ((a garota ri))

T7 T: o papai tá comendo tudo P. ((olha para P.))

T8 V: ((passa a colher no prato e a leva novamente à boca do fantoche))

(...)

T9 T: e olha quem tá aqui $(+)$ O PAULO $(+)$ eu achei o PA::ULO ((pega outro fantoche e o chama de Paulo))

T10 P: nã $(+)$ tia $(+)$ qué ((aponta para o fantoche que a T. está segurando))

T11 T: o que você quer "

T12 P: QUÉ

T13 T: o que você quer "

T14 P: Pá ((aponta para o fantoche da T.))

T15 T: você quer o quê " o Paulo "

T16 P: é ((realiza meneio positivo com a cabeça))

Observa-se, neste episódio, que a terapeuta incita a interação comunicativa, bem como explora a imaginação das duas crianças. Com isso, nota-se nos turnos 2, 4 e 8, que V. apresenta intenção em se comunicar, interagindo com a terapeuta no contexto da brincadeira de faz-deconta. A criança compreende o sentido da comunicação verbal da terapeuta, agindo de acordo com o contexto. V. distingue a fala da terapeuta e a do personagem que ela estava representando através de sua voz, realizando gesto representativo contextualizado (turnos 4 e 8). V. consegue, portanto, dar sentido a brincadeira ao alimentar o fantoche e não a terapeuta, após esta dar vida ao boneco e dizer que estava com fome.

No turno 9, nota-se que a terapeuta interage com as crianças mostrando-lhes o fantoche que havia encontrado. A partir disto, P. utiliza a comunicação verbal, através de palavras monossilábicas distintas e gestos indicativos, com o intuito de compartilhar sua atenção com a terapeuta sobre o objeto que desejava (turno 10). A terapeuta, então, passa a dar um significado à comunicação verbal de P. fazendo-lhe a mesma pergunta, duas vezes (turnos $11 \mathrm{e}$ 13). Deste modo, observa-se que P. mantém a interação com ela utilizando a comunicação verbal para ser compreendida (turnos 12, 14 e 16) tentando, até mesmo, reproduzir o nome do fantoche dado inicialmente pela terapeuta (turno 14).

\section{Discussão}

Inicialmente, $\mathrm{V}$. apresentava grandes dificuldades em interagir tanto com a outra criança quanto com a terapeuta, evitando o contato ocular, procurando o isolamento, apresentando interesses restritos a determinados objetos, ausência de oralidade e dificuldades com a comunicação 
não-verbal. Porém, no decorrer do processo terapêutico, a inserção de V. no contexto da brincadeira de faz-deconta, pela terapeuta, como um sujeito que é compreendido e aceito pelos outros, possibilitou um incentivo à criança, motivando-a a utilizar formas de comunicação não-verbais para interagir. De acordo com Pino (2005), o surgimento da atividade simbólica da criança não é fruto de sua descoberta espontânea, nem mesmo de operações intelectuais e de um processo de condicionamento. Ela pode ser encontrada na esfera das relações sociais, "pois é com os homens e por intermédio deles que ela descobrirá a significação e o valor das coisas" (p. 159).

A partir do episódio 2 ( $15^{\mathrm{a}}$ sessão) notou-se maior interação comunicativa de V. em contexto lúdico, utilizando os brinquedos com uma finalidade simbólica. No episódio 3, é possível observar a iniciativa de V. em interagir com a terapeuta e com a outra criança através de gestos representativos (gestos realizados a partir da utilização dos brinquedos para interação com o outro) e gesto de negação (meneio negativo com a cabeça). Notase, portanto, a partir de colocações de Vigotski (1984/ 2007), que o brinquedo simbólico pode ser compreendido como um sistema de "fala", a partir de "gestos que comunicam e indicam os significados dos objetos usados para brincar" (p. 130). Assim, grandes progressos foram observados para uma criança com comportamentos autísticos: a busca por interação com a terapeuta e a outra criança através do contato ocular, expressões faciais e gestos representativos durante as atividades, demonstrando, portanto, intenção em se comunicar.

No início dos atendimentos terapêuticos realizados, P. frequentemente apresentava movimentos estereotipados com o corpo, interesse em movimentar objetos, dificuldade em manter a atenção à atividade proposta pela terapeuta, emitia sons estereotipados e apresentava dificuldades em participar das atividades com a terapeuta e outra criança, demonstrando-se agressiva muitas vezes. Em contra partida, na $1^{\text {a }}$ sessão realizada (episódio 1), embora tenha apresentado comportamentos como estes, também demonstrou iniciativa na interação com a outra criança, tentativa de chamar a atenção da terapeuta e utilização de alguns brinquedos com finalidade simbólica. No decorrer das sessões terapêuticas, com a mediação da terapeuta, passou a interagir cada vez mais, apresentando maior intenção em se comunicar e compartilhar a atenção com o outro sobre determinados objetos e situações na brincadeira.

Observou-se desenvolvimento da comunicação verbal de P. e a utilização do gesto como apoio. Apresentou desenvolvimento interacional sendo observadas cenas de atenção conjunta entre ela e a terapeuta. Para Tomasello (2003), o envolvimento da criança em interações de atenção conjunta passa a ocorrer quando ela começa a compreender as outras pessoas como agentes intencionais iguais a ela.

Durante os atendimentos terapêuticos realizados, podese observar, portanto, o desenvolvimento da interação comunicativa entre estas crianças e entre estas e a terapeuta e compreender como esta interação ocorreu durante todo este processo em contexto lúdico. A brincadeira de faz-de-conta realizada em dupla configurou-se como uma situação favorável para a interação social e o desenvolvimento comunicativo dos sujeitos envolvidos. Segundo Alves et al. (2007), "quando em suas interações comunicativas as crianças estabelecem com seus parceiros um setting de faz-de-conta, estabelece-se uma estrutura interativa que dá suporte a entrada do sujeito na coletividade, a partir da possibilidade de compartilhar significados" (p. 328).

Embora esta pesquisa não tenha a intenção de analisar a intervenção terapêutica realizada, observou-se a importância do terapeuta durante este processo interacional. Para Pino (2005), na medida em que o outro confere às ações da criança um significado, esta vai incorporando a cultura que a constitui como um ser cultural, lhe dando condições para comunicar-se com os outros. Segundo Pinto e Góes (2006), o "destino" de crianças que apresentam algum déficit depende das suas relações com os outros, de sua inserção em esferas distintas de atividade da cultura e das experiências qualitativas vividas, encontrando desta maneira, as bases para construir suas funções internas. Neste contexto, a inserção da terapeutapesquisadora no campo investigado possibilitou uma participação ativa nestas novas relações sociais (interação pesquisadora-sujeitos), sendo, portanto, todos os envolvidos considerados sujeitos da mesma pesquisa.

Igual importância teve a presença das duas crianças neste processo, possibilitando o compartilhamento de experiências entre elas. Os atendimentos realizados em dupla proporcionaram a ampliação de experiências interacionais e vivências comunicativas entre as duas crianças e entre elas e a pesquisadora-terapeuta devido à mediação desta através da linguagem, no contexto de brincadeiras de faz-de-conta.

Reconhecer o papel fundamental do meio social no desenvolvimento cognitivo de uma criança permite observar cuidadosamente a história de vida de cada sujeito e relacioná-la com as dificuldades enfrentadas por eles. De acordo com Fernandes (2004), colher informações sobre a história orgânica, social e emocional da criança pode representar o início do processo de construção da compreensão de seu caso clínico.

No decorrer do processo terapêutico, após 3 meses do início da pesquisa observou-se que uma das crianças (P.), apresentou desenvolvimento significativo relacionado à interação, desenvolvimento simbólico (brincadeiras de faz-de-conta) e comunicativo. Desta forma, a criança foi encaminhada, pela terapeuta-pesquisadora, para uma nova avaliação com a médica psiquiatra (que lhe deu o primeiro diagnóstico) que constatou quadro clássico de síndrome de Down sem diagnóstico de autismo. Portanto, de acordo com a observação das histórias sociais e emocionais, além do desenvolvimento cognitivo destas duas crianças, notou-se que a presença de tais comportamentos pode 
Castro, G. S., Panhoca, I., Zanolli, M. L. (2011). Interação Comunicativa em Contexto Lúdico de Duas Crianças com Síndrome de Down, Comportamentos Autísticos e Privação de Estímulos.

estar relacionada à privação de estímulos e ausência de oportunidades esperadas. Para Coelho et al. (2008), “o desenvolvimento da criança é resultante da interação entre suas capacidades potenciais e a influência de seu ambiente. Uma insuficiência de estimulações sensoriais, afetivas e sociais tem como conseqüência um atraso do desenvolvimento das esferas cognitiva, afetiva e relacional" (p. 76).

Reforça-se aqui a ideia de que mesmo crianças que apresentam um déficit de caráter biológico determinado por uma síndrome, no caso a síndrome de Down, podem apresentar bom desenvolvimento cognitivo se oportunidades forem dadas a elas para que possam superar suas dificuldades. De acordo com Vigotski (1997), a criança, ao se deparar com alguma dificuldade, tem a possibilidade de avançar por uma via indireta para vencê-la. É do processo de interação da criança com o meio que se criam situações que a impulsionam para o caminho da compensação. Em contra partida, de acordo com De Carlo (1999), afastar o deficiente do meio social e restringir suas interações e vínculos sociais impede que este receba a "alimentação" cultural ideal para o seu desenvolvimento, levando-o à acumulação de fatores secundários ou complementares ao quadro primário da deficiência mental. No caso das crianças deste estudo, os comportamentos autísticos associados à síndrome de Down podem estar relacionados à história de vida de cada um, com histórias de abandono pela mãe e privação de estímulos. Cabe ressaltar ainda que um diagnóstico médico não é uma descoberta estagnada, mas o início de uma compreensão para a disponibilização de oportunidades terapêuticas e educacionais a estas crianças.

\section{Conclusão}

As crianças apresentaram melhor desenvolvimento qualitativo na interação comunicativa tanto entre elas quanto entre elas e a terapeuta. Apresentaram maior intenção comunicativa e interesse na interação, a partir da comunicação não-verbal e introdução da verbal (em uma das crianças), durante brincadeiras de faz-deconta. Tais brincadeiras configuraram-se como situações extremamente favoráveis por possibilitarem vivências interativo-linguísticas ricas e construtivas.

Levando-se em consideração o bom desenvolvimento na interação comunicativa destas duas crianças, bem como suas histórias de vida, pode-se observar que os comportamentos autísticos apresentados por elas podem ter relação com a privação de estímulos que tiveram e ausência de oportunidades esperadas para um bom desenvolvimento interativo-comunicativo.

Observou-se que proporcionar a estas crianças oportunidades terapêuticas para a compensação de suas dificuldades, não as "rotulando" a partir de seus diagnósticos e nem as restringindo de acordo com suas dificuldades comportamentais, cognitivas e comunicativas, permitiu que estas mostrassem condições de se constituírem como sujeitos sociais comunicativos em contexto interativo. Porém, cabe ressaltar que, oferecer-lhes oportunidades somente em âmbito terapêutico não é suficiente para que possam superar suas dificuldades. É preciso que elas sejam inseridas em ambientes sociais construtivos distintos (terapêuticos, educacionais e com os familiares/responsáveis), para que possam vivenciar experiências desejáveis para um bom desenvolvimento global.

\section{Referências}

Alves, A. C. S., Dias, M. G. B. B., \& Sobral, A. B. C. (2007). A relação entre a brincadeira de faz-de-conta e o desenvolvimento de habilidades na aquisição de uma teoria da mente. Psicologia em Estudo, 12, 325-334.

American Psychiatric Association. (1995). DSM-IV- Manual diagnóstico e estatístico de transtornos mentais (4. ed.). Porto Alegre, RS: Artes Médicas.

Andrade, R. V., \& Limongi, S. C. O. (2007). A emergência da comunicação expressiva na criança com síndrome de Down. Pró-Fono Revista de Atualização Científica, 19, 387-392.

Ballone, G. J. (2004). Crianças adotadas e de orfanato. Retrieved February 10, 2009, from http:// www.virtualpsy.locaweb.com.br/index.php?art=52\&sec=19

Borges, L. C., \& Salomão, N. M. R. (2003). Aquisição da linguagem: Considerações da perspectiva da interação social. Psicologia: Reflexão e Crítica, 16, 327-336.

Castillo, H., Patterson, B., Hickey, F., Kinsman, A., Howard, J. M., Mitchell, T., et al. (2008). Difference in age at regression in children with autism with and without Down syndrome. Journal of Developmental \& Behavioral Pediatrics, 29, 8993.

Coelho, A. C. C., Iemma, E. P., \& Lopes-Herrera, S. A. (2008). Relato de caso: Privação sensorial de estímulos e comportamentos autísticos. Revista da Sociedade Brasileira de Fonoaudiologia, 13, 75-81.

Cunningham, C. (2008). Síndrome de Down: Uma introdução para pais e cuidadores. Porto Alegre, RS: Artmed.

De Carlo, M. M. R. P. (1999). Se essa casa fosse nossa ...: Instituições e processos de imaginação na educação especial. São Paulo, SP: Plexus.

Fernandes, F. D. M. (2004). Terapia de linguagem em crianças com transtornos do espectro autístico. In L. P. Ferreira, D. M. Befi-Lopes, \& S. C. O. Limongi, Tratado de Fonoaudiologia (pp. 941-953). São Paulo, SP: Roca.

Freitas, A. P., \& Dainêz, D. (2006). Possibilidades de comunicação de um jovem com síndrome de Down durante o trabalho terapêutico-fonoaudiológico em grupo. Revista da Sociedade Brasileira de Fonoaudiologia, 11, 188-193.

Gadia, C. A., Tuchman, R., \& Rotta, N. T. (2004). Autismo e doenças invasivas de desenvolvimento. Jornal de Pediatria, 80(Supl.), S83-S94.

Góes, M. C. R. (2000). A abordagem microgenética na matriz histórico-cultural: Uma perspectiva para o estudo da constituição da subjetividade. Caderno Cedes, 20, 9-24.

Gori, R. M. A. (2006). Observação participativa e pesquisaação: Aplicações na pesquisa e no contexto educacional. Itinerarius Reflectionis, 1, 113-120.

Halpern, R., \& Figueiras, A. C. M. (2004). Influências ambientais na saúde mental da criança. Jornal de Pediatria, 80(Supl.), S104-S110. 
Hueara, L., Souza, C. M. L., Batista, C. G., Melgaço, M. B., \& Tavares, F. S. (2006). O faz-de-conta em crianças com deficiência visual: Identificando habilidades. Revista Brasileira de Educação Especial, 12, 351-368.

Kent, L., Perry, D., \& Evans, J. (1998). Autism in down's syndrome: Three case reports. SAGE Publications, 2, 259267.

Klin, A. (2006). Autismo e síndrome de Asperger: Uma visão geral. Revista Brasileira de Psiquiatria, 28, 3-11.

Marcuschi, L. A. (2007). Análise da conversação (6. ed.) São Paulo, SP: Ática.

Organização Mundial da Saúde. (1993). Classificação de transtornos mentais e de comportamento da CID-10: Descrições clínicas e diretrizes diagnósticas. Porto Alegre, RS: Artes Médicas.

Passerino, L. M., \& Santarosa, L. C. M. (2007). Interação social no autismo em ambientes digitais de aprendizagem. Psicologia: Reflexão e Crítica, 20, 54-64.

Pino, A. (2005). As marcas do humano: Às origens da constituição cultural da criança na perspectiva de Lev. S. Vigotski. São Paulo, SP: Cortez.

Pinto, G. U., \& Góes, M. C. R. (2006). Deficiência mental, imaginação e mediação social: Um estudo sobre o brincar. Revista Brasileira de Educação Especial, 12, 11-28.

Rodrigues, E. C., \& Alchieri, J. C. (2009). Avaliação das características de afetividade em crianças e jovens com síndrome de Down. Psico-USF, 14, 107-116.

Skuse, D. H. (2002). Privações extremas na primeira infância. In D. Bishop \& K. Mogford, Desenvolvimento da linguagem em circunstâncias excepcionais (pp. 27-50). Rio de Janeiro, RJ: Revinter.

Starr, E. M., Berument, S. K., Tomlins, M., Papanikolaou, K., \& Rutter, M. (2005). Brief report: Autism in individuals with Down syndrome. Journal of Autism and Developmental Disorders, 35, 665-673.

Subirachs, R. G. (2005). Transtornos neurológicos y el niño con síndrome de Down. In J. M. Corretger, A. Seres, J. Casaldáliga, \& K. Trias, Síndrome de Down: aspectos médicos actuales. Barcelona, España: Masson.

Tomasello, M. (2003). Origens culturais da aquisição do conhecimento humano. São Paulo, SP: Martins Fontes.

Vigotski, L. S. (1997). Obras escogidas: Vol. 5. Fundamentos de defectología. Madrid, España: Visor.

Vigotski, L. S. (2007). A formação social da mente: O desenvolvimento dos processos psicológicos superiores (7. ed.). São Paulo, SP: Martins Fontes. (Original work published 1984) 